\title{
Correction to: Identification of a Seasonal Subsurface Oxygen Minimum in Rivers Inlet, British Columbia
}

\author{
Jennifer M. Jackson ${ }^{1} \mathbb{D}$. Sophia Johannessen ${ }^{2}$. Justin Del Bel Belluz ${ }^{1}$ Brian P. V. Hunt ${ }^{1,3,4} \cdot$ Charles G. Hannah $^{2}$
}

Published online: 23 September 2021

(c) Coastal and Estuarine Research Federation 2021

\section{Correction to: Estuaries and Coasts https://doi.org/10.1007/s12237-021-00999-y}

Due to a typesetter error, Fig. 1 was corrected in the original article.

The original article can be found online at https://doi.org/10.1007/ s12237-021-00999-y.

Jennifer M. Jackson

Jennifer.jackson@hakai.org

1 Hakai Institute, Victoria, BC, Canada

2 Fisheries and Oceans Canada, Institute of Ocean Sciences, Sidney, BC, Canada

3 Institute of Oceans and Fisheries, University of British Columbia,, Vancouver, BC, Canada

4 Department of Earth, Ocean and Atmospheric Sciences, University of British Columbia, Vancouver, BC, Canada 